\title{
THE PROFESSION AND
}

\section{PRACTICE OF NUTRITION \\ AND DIETETICS IN SUDAN}

\section{Elham Aljaaly}

Head of the Clinical Nutrition Department, Faculty of Applied Medical Sciences,

King Abdulaziz University,

P.O. Box 54539, Jeddah 21524, Saudi Arabia

Fax: 00966216402000/24251

E-mail: ealjaaly@kau.edu.sa

E-mail: aljaalydiet@gmail.com 


\begin{abstract}
Purpose: The purpose of this review is to examine the available evidence on defining professionalism and dietetic practice in Sudan.

Design/Methods: A comprehensive search of six electronic databases including ISI, Medline, PubMed, EMBASE, Health Management Information Consortium (HMIC) and PsycINFO was conducted in March 2015 to find evidence related to professionalism and standards of dietetic practices in Sudan.

Findings: There is a lack of significant prior research on professionalism and practice specific to the field of nutrition and dietetics in Sudan.

Social Implications: Based on the results of the review, we urgently call for dietetic professionals to assemble a group of leaders and thinkers, particularly dietetic educators and researchers, to help in the development of professionalism of the field of dietetics and to unify the dietetic practice in Sudan.

Originality and Value: By adopting the methodology of reviewing published papers, we can identify gaps in professionalism in the field of dietetics. We can also identify sustainable dietetic practices in Sudan, which could stimulate new research agendas in this area.
\end{abstract}

Keywords: professionalism; profession; dietetic practice; nutrition; dietetics; Sudan.

Reference to this paper should be made as follows: Aljaaly, E. (2016) 'The Profession and Practice of Nutrition and Dietetics in Sudan, Int. J. Sudan Research, Vol. 6, No. 2, pp.90-102.

\title{
INTRODUCTION
}

\section{Overview of the problem}

Although Sudan has basic education programmes for nutrition and dietetics, which was established earlier in comparison to other Arab and African countries (in addition to the further education), there are no unified national standards for these programmes, specifically in relation to the course content, examinations, student assessment and/or supervised practical placement. In addition, no national dietetic organisational body is present. This type of association is important to ensure that dietetic practice is strong, effective and innovative. The association could help to accredit dietitians and to inform, protect, represent and support members. A National Dietetic Association (NDA) would also be responsible for defining the Code of Ethics and Practice and in ensuring continuous professional development.

In Sudan, the doctor versus population ratio is well known and has been reported to be nearer to international benchmarks (HRH Sudan, 2013). However, this is not the case with other cadres including dietetics, which might result in a skill-mix inequity. Moreover, the number of dietitians working in clinical and non-clinical areas is not well known in Sudan. There are many experts and professionals working abroad who have participated in establishing some academic and clinical programmes in both public and governmental sectors.

It is important to review the whole system of nutrition and dietetics in Sudan. This is in order to raise awareness of the standards of education and training. It will also help to emphasise the range in the practice of dietitians and to continually update knowledge of employment situation of the profession in the country. 


\section{The target Audience}

While the emphasis on the situation of professionalism and dietetic practice in Sudan is an important feature of an effective review, this requirement has to be with the need to make the review relevant to a broad range of professionals. This may be accomplished by discussing the wider implications of the reviewed topic for other Arab and African countries and might even be relevant to other health professionals.

\section{Clinical relevance of the problem}

In order to promote the profession of dietetics and to avoid a shortage of qualified dietitians, we need greater understanding of the profession and related practices through reviews and continuous surveys of professionals inside Sudan. Dietitians with work experience in countries other than where they were educated may also help in use of skills and resources to their full potential.

\section{Professionalism and dietetic education}

Unrelatedly to the field, it is commonly acknowledged that a profession includes a definite form of information, completion of a designed course of study, examination and certification or licensure by some kind of regulatory agency, which has disciplinary rules (Sallot et al., 1998).

Education of health professions traditionally follows in silos with diverse schools and curricula for each cadre leading to basic qualification to enter the profession. This trend is usually maintained in post-graduate studies and further training.

Professionalism is defined as "the conduct, aims, or qualities that characterise or mark a profession or a professional person” (Merriam-Webster, 2015). Although, the framework of professional behaviour relates to professionalism, specific conduct or qualities are difficult to define and identify.

For the field of dietetics, the term 'professional conduct' has been organised to incorporate professionalism. Moreover, professionalism was emphasised to show respect and concern for people, be knowledgeable and keep current with the latest research in one's area of practice, adherence to the firmest ethical standards, and obligation to the profession (Payne-Palacio and Canter, 2000; Rodriguez et al., 2000).

Research confirmed that the formal educational setting is the most powerful time for the expansion of professionalism. Therefore, curriculum recommendations that address professionalism within the dietetic curriculum shouldbe developed. This confirms the importance of identifying specific professional behaviours and their development within the structured dietetic curriculum, particularly for dietetic educators who should be focusing on teaching professional behaviours during this time period (Golzynski, 2001). Therefore, a common global terminology/standardised language for the profession of dietetics is required. This is in order to gain a superior understanding of the content and standard of dietetic education courses and the characters dietitians play (ICDA, 2008). 
The International Confederation of Dietetic Associations (ICDA) defines the profession of dietetics as

"A dietitian is a person with a qualification in Nutrition \& Dietetics recognised by a national authority. The dietitian applies the science of nutrition to the feeding and education of groups of people and individuals in both health and disease".

Some of the ICDA and European Federation of the Association of Dieticians (EFAD) members (from 41 countries) are applying the ICDA definition. 71\% of these members (20 countries) have a standard title used for a dietician. Mostly, these dieticians are Registered Dieticians (RD) (ICDA, 2008).

The dietetics profession is independently growing worldwide, with forward-thinking leaders, and the emergence of dietitians as leaders within those local communities concerned with their health and well-being (Winterfeldt et al., 2011).

In each country, the profession of dietetics crystallises itself over time to organise and regulate its members in the forms of professional associations or regulatory councils. Each professional association should inform, protect, represent and support its members.

As a profession, dietetics has established standards for practitioner education through different international associations for dietetics such as the American (A.N.D.), Canadian (CDA) and Australian (DAA).

In 2004, the ICDA suggested a bachelor degree as a minimum level of education for a dietician with a period of supervised professional practice of at least 500 hours (ICDA, 2008). However, the EFAD concluded that the education and work of dieticians in Europe is complex and multilayered.

The EFAD referred this complication to the different cultures in each country that give rise to different expectations from professionals, politicians and the public (EFAD, 2005).

\section{Dietetic practice for dietitians}

Dietitians are independent practitioners who work within an ethical framework. In addition to principals for practitioner education, dietetics' associations have recognised a policy of ethics, registration and licensure systems, and a tradition of partnership and cooperation with others in areas that are considered allies of specialised practice to increase out reach and service.

A Code of Ethics in the field of dietetics is provided by many international professional organisations to their members. These ethics give guidance to members in terms of ethical and moral behaviour, integrity, fairness, unselfishness and consideration (ADA, 1999).

Dietetic associations are aiming to support their members as they apply for a wide variety of the profession, and reach out to the public with suitable and consistent information about food and nutrition issues (Anderson, 2013). Some of these associations support their members' practice in an extensive diversity of careers, and to reach out to the public with suitable and trustworthy information about food and nutrition issues (Winterfeldt et al., 2011). In 2008, twenty-five (25) countries that have NDA, reported to have certain standards to accredit dietitians and provide them with the full membership (ICDA, 2008). 
Therefore, Quality and Performance, Scope/Standards of Practice, and Accreditation Organisations are monitored by NDA to ensure the quality of nutrition services and provide guidelines for safe and operative patient care (JAND, 2013).

The history of the dietetics profession shows involvement in different practices such as growth, assessment of nutritional status and management of nutrition-related diseases.

Dietetic Practice Groups (DPGs) are formed by the international dietetic association for members to practice or have a particular importance in a well-known area of practice. DPGs require a good network of connections amongst group members. The groups choose a representative, collect and print a newsletter or comparable contact lists for its members.

\section{Areas of Practice}

The practice of dietetics is planned around different areas that employ dieticians. These mostly include management, medical community and nutritional instructions. Other areas are designated hospital-related dietetics, which includes paediatrics, renal, acute admission to hospital, and an ambulatory patient, in addition to patients those require care for long-term.

ICDA has also defined the scope of dietetic practice for dietitians as they may work in a variety of settings, mainly in areas of clinical practice such as acute care/in patient care, hospitals, ambulatory care, long-term care, nursing homes and assisted living facilities.

Each country has its own credentials for academic and professional education and may differ in the scope of their nutrition and dietetic practices. In order to promote the profession and cover the shortage of qualified dietitians, which is reported around the world, it is as important for dietitians, as it is for other healthcare professionals, to continue to develop their knowledge and understanding of both education and the work/practice. This will encourage dietitians, even at entry-levels to practice and achieve higher levels of performance of the job tasks and functions within the profession (Dietitians of Canada, 2012).

Regular meeting at the national, regional and international level are required to help dietitians develop a greater understanding of the profession and for standardisation of the practice. This also helps to support dietitians who would like to work in countries other than where they were educated. Greater understanding would ensure the use of these valuable skills and resources to their full potential (ICDA, 2008).

The purpose of this comprehensive literature review is to examine the available evidence and present the most current research for the profession of dietetics in Sudan, to review the history of the development of the field of dietetics over time, to define and specify professional skills for dietetic practitioners, and to assess the scopes of dietetic practices for dietitians in the country of Sudan.

The literature review was broken down rationally into two main sections: professionalism and dietetic practice. We ope this review will help the leaders and futurists in the field of dietetics (within and outside of Sudan) to define the need for the development and changes within the profession. 


\section{DESIGN/METHODS}

\section{Searching for the literature}

\section{Targeted search}

A comprehensive search of six electronic databases including ISI, Medline, PubMed, EMBASE, Health Management Information Consortium (HMIC) and PsycINFO to April 2015 was conducted to find evidence related to the profession of nutrition and dietetics, professionalism and standards of dietetic practices in Sudan.

\section{Search strategy}

The following keywords were used in varying combinations to identify relevant primary (collected by the researcher) and secondary studies (collected by others to be 're-used' by the researcher).

The search for the first part of the literature used the following keywords:

The terms 'profession', 'professionalism', 'professionalisation', 'identity', 'dietetics', 'codeethics', 'dieticians' and 'professional', were used to establish the sample.

The search for the second part of the literature used the following keywords:

The terms 'nutrition', 'dietetics', 'dieticians', 'code ethics', 'dietetic education', 'practice' and 'professional', were used to establish the sample.

The reference lists of published works were also searched for additional sources.

The search included MeSH and text, word terms with combination using and or Boolean operator.

A number of specialised electronic Journals in the field of nutrition and dietetics were also searched. In addition, Electronic Theses online Services (ETHoS) was searched using the above search terms, and theses related to both parts of the search were included. The general search engines revealed government reports, discussion papers, expert opinion, personal contacts with academic staff and working dieticians inside/outside Sudan, information from websites, popular media and articles in newspapers and magazines and personal contacts. Communication with experts in the field in Sudan were equally important and these were retrieved to find relevant information.

Policy statements, consultation papers and periodicals were examined to abstract evidence related to the present literature review questions. Official Sudanese reports such as those from the Federal Ministry of Health, Sudan, national (soft/hard copies) reports that included the dietetic education and nutrition and dietetic services were also considered. Reports by international dietetics organisations such as International Conferadration of Dietetic Association (ICDA), which includes information about dietitians (their education and work)in different countries, were also included. The WHO Library Cataloguing-in-Publication Data were also searched to find relevant literature. 


\section{Selecting resources for review}

\section{Inclusion and exclusion criteria}

All articles (i.e. reviews, service evaluation, practice, populations, interventions, crosssectional, expert opinions or outcomes of searches), statists and reports (national and international, educational institution, governmental in the form of hard or soft copies) related to Sudan were included.

\section{Topics of interest}

Criteria used to select articles and reports for review were professionalism for dietitians in the country of Sudan, profession of dietetics in Sudan, dietetic education systems and programmes in Sudan, employment status of dietitians, scope of dietetic practice, history of the development of the field of dietetics, professions and leaders and thinkers in the field of dietetics (within and outside of Sudan).

\section{Evaluating the evidence}

Final selection of articles and reports are done througha careful review of each article and report. Examined resources, particularly governmental reports were careffuly reviewed by two persons(the main author and Sudanese experts in the field). This was done to avoid errors in reporting results of the review.

\section{RESULTS AND DISCUSSION}

Computerised databases are efficient and effective. However, little data was found to examine the scope of the present literature review with regards to professionalism and practice specific to the field of nutrition and dietetics in Sudan.

The findings of the review concluded that Sudanese researchers previously conducted no specific reviews or surveys in the field of nutrition and dietetics to quantify and qualify the related data in Sudan. However, this is important to define the need for the development and changes within the profession. Furthermore, this review included reports from the grey literature (government andacademic literature produced in print and electronic formats), unpublished work and personal communications with the experts in the field that could contribute additional sources of information related to the search objectives.

There view showed that some other international organisations such as ICDA and the WHO have included in their surveys some data concerning the dietetic profession in Sudan. Yet, lack of national data makes proper monitoring and evaluation ofthe profession difficult.

\section{Professionalism and dietetic education in Sudan}

Level of basic education and professional title

In 2004, the ICDA suggested a bachelor degree as a minimum level of education for a dietitian with a period of supervised professional practice of at least 500 hours (ICDA, 2008). 
Based on the ICDA report in 2008, a number of its members do not have basic dietetic education programmes in their country and dieticians receive their education in other countries that teach the programme (ICDA, 2008).

In Sudan, basic education in Nutrition and Dietetics field leads to a Bachelor degree and academic courses leading to a major diploma, a Masters degree or a PhD are available (ICDA, 2004). In Sudanese university such Ahfad University for Women (AUW), a degree level education program is offered and the actual time taken to receive the degree varied from 3 years to $4 \frac{1}{2}$ years.

Three main universities in Sudan are leading basic programmes in nutrition and dietetics (A. A. Abdalla, personal communication, April 18, 2015) and the websites of the three universities).

The University of Khartoum, provides a programme under the Faculty of Education and Department of Family Sciences - The programme is under the name of Nutrition and Dietetics. It was established in 1966 under the College of Agriculture (Home Economics). In 1980, the programme was changed to be under the Department of Family Sciences. In the period from 1981 to 1998, the total number of graduates from the programme was about 340 .The number of graduates in the period from 1999 to 2015 was 1120 students. Graduates who complete the programme are graduated as Clinical Dietitians. Based on the last modification ofthe study plan in 2012, graduates should complete a total of 90 credit hours in 5 academic years. However, no practical programme (practicum/internship) is required for graduates to receivethe qualification, although some training is included as part of some courses (A. A. Gadah-eldam, received April 18, 2015). In addition, no detailed information was found about the study plan or if the programme ( 90 credit hours) included subjects not directly related to dietetics, for example, language, religion or first aid. Moreover, it was not clear if the study plan included a graduation project/study report. The total number of graduates from the Bachelor degree programme (BSc) to present is about 1460.

The faculty also offers graduate programmes such as Masters degree (MSc) and Doctor of Philosophy $(\mathrm{PhD})$ in Nutrition. The total number of graduates from the Masters degree programme is about 500. The total number of graduates from the PhD degree programme is approximately 30 .

In AUW, the food and nutrition programme is offered by the School of Health Science, which was established in 1966. However, recently the programme was changed to be under the Faculty of Health and Medical Sciences. The actual time taken to receive the degree is five years. Options and specialisations related to the food and nutrition programme include: Applied Nutrition, Clinical Nutrition, Nutrition Program Management, Nutrition Problems Seminar, Mother and Child Nutrition, Food and Nutrition Policy and Planning and Research Project. No compulsory practical programme is required to receive the degree. Other qualifications that allow the practice as adietitian include MSc and PhD degrees, either as a first qualification or after completing a bachelor degree.

These awards are in human nutrition and are under the Nutrition Centre for Training and Research (NCTR), which was established in 2002. The centre addresses some health and nutrition issues in the community. Other objectives of the NCTR is to work as a focal point for all health and nutrition activities in the country, to provide training for those working in this field at different levels (short and long-term training programs), promote research, provide health and nutrition information services and the provision of technical and professional assistance to governmental and local NGOs, in addition to the educational institutions (Prof. S. Washi, personal communication, March 26, 2015). 
From Alribat National University, two batches of students in 2014 and 2015 graduated from the bachelors degree programme. Graduates have a professional titleas Clinical Nutritionists. The graduates were about 140. About 24 students are doing their Masters in Clinical Nutrition.

\section{Dietetic practice for dietitians in Sudan}

\section{Membership accreditation of the NDA}

Dietitians must be graduates of an approved programme of education and registered with a professional regulation body or a NDA, which should be recognised by a government body as providing expert opinion in nutrition and dietetics. NDAs also have certain standards to accredit dietitians and provide them with the full membership. In 2008, 25 members of the ICDA reported having NDAs (ICDA, 2008).

In Sudan, dietetics students are registered nation wide and most of the graduates are practicing the profession in either government organisations or in the private sector. However, their full registration is provided by the Sudanese National Council for Medical and Health Professionals, which is considered the authorised professional organisation for the full registration for all health professionals including dieticians. This is comparable with what is followed in other Arab Countries, such as Saudi Arabia, where dietetic services is not guided nationally by the authorised professional organisation Saudi Dietetic Association (SDA), which is been established earlier (Aljaaly and Khalifa, 2015).

Studies looking at dietetics in Africa, reported that few dietetics organisations exist, with the Association for Dietetics in South Africa being the most formally organised and developed. The report showed the presence of organisations in Sudan and Nigeria. However, reports about countries where dietitians have been working did not include dieticians from Sudan. Moreover, reports in 1985 and 1991 by the East, Central and Southern Africa Food and Nutrition (ECSAFAN) Cooperation about dietitians and nutritionist positions for food and nutrition programmes did not define well the role of the dietitian, which is not understood in Africa. Furthermore, the dietitian and nutritionist are possibly regarded as being the same (Bloch, 2007; Debbi et al., 2011).

However, 'to our knowledge' no NDA is available in Sudan to guide the profession. Establishing an NDA in Sudan could enhance the professionalism in a healthcare field of dietetics, which needs to be supported by a strong work ethics and a commitment to standards of performance far above the ordinary. Moreover, it could support leadership skills and the strengthening of Human Resources for Health $(\mathrm{HRH})$ concerning the profession of dietetics ( $\mathrm{HRH}, 2011)$. It is, therefore, clear that there is a need to develop a unified teaching and assessment method regarding professionalism among undergraduate health professional students (ADA, 2008).

\section{Estimated number of working practicing dietitians}

In Sudan, healthcare is delivered through teaching, general and specialist hospitals, which have a varying number of specialties and beds providing secondary and tertiary care. Rural hospitals provide secondary care and diagnostic facilities. Primary healthcare also plays a role in delivering healthcare in the country (WHO, 2009). In Khartoum, there are about 48 State Public hospitals. Among these hospitals, 31 have nutritionists who are basically working 
under food service departments and are responsible for providing meals for patients. Seven hospitals provide health education and counselling for patients. However, no food services are provided. The other 10 hospitals do not provide any type of nutrition services for patients. Moreover, there are about 500 health centres under the State Ministry of Heath Plan and only 21 of these health centres employing nutritionists (A. A. Abdalla, personal communication, April 18, 2015).

According to the WHO benchmark of 2.28 per 1000 population, Sudan is considered within the critical shortage zone for health professionals in general. This is calculated as a ratio of 1.23 health professionals per 1000 population (Sudan WHO, 2012). However, doctor versus population ratio is closer to the international levels (HRH Sudan, 2013). The ICDA reported in 2004 that the number of Practising Dietitians per 100,000 members of the population in Sudan is between one and two $(>1-<2)$. Most of the practitioners are working in either government organisations or in the private sector.

The development of effective strategies for improving health services was recommended by World Health Organization (WHO) for a number of countries including Sudan, which led the National Human Resources for Health to develop the (2012-2016) Strategic Plan for Sudan. The strategy is inclusive and its document shifting from the long-established concept of training and healthcare work force numbers to the wider continuum of $\mathrm{HRH}$. The HRH strategic plan was developed based on a methodical situational analysis as well as using the HRH action framework as a guide for its expansion. The HRH strategic plan was developed by the General Directorate of Human Resources for Health Development (GDHRD) (NHRH, 2011).

The (2012-2016) proposed Health Strategic Plan for Sudan (NHRH) has considered the importance of developing the health professions including dietetics. In addition, a call for experts' participation in the development, particularly for the Diaspora of Sudanese physicians and healthcare professionals in addressing the development of $\mathrm{HRH}$ issues was strongly recommended. Therefore, this review confirms the need to include diasporas of Sudanese professionals in the field of nutrition and dietetics in this issue. The call is to include those have experience in the academic and/or clinical practice. These professionals can participate effectively in supporting the development of the professionalism and practice of dietetics in Sudan. This consequently will help in supporting future efforts to address dietetic work force issues in Sudan (NHRH, 2011).

Consequently, in 2013 the National Council of Medical Professions has adopted new strategies concerning updating the profession of Dietetics for proper practice in hospitals. This was in collaboration with the Ministry of Higher Education and Federal Ministry of Health. The strategy published new guidelines for practice as an attempt to improve educational programmes and practice in the field (NCMP, 2013; A. A. Abdalla, personal communication, April 18, 2015).

\section{CONCLUSION AND RECOMMENDATION}

There is a lack of significant previous research on professionalism and practice specific to the field of nutrition and dietetics in Sudan.

Dietetics is an evidence-based profession with research and outcome evaluation at its core. Based on the results of the review, there is a need to have information about dietetics practice in Sudan readily available and accessible through the internet as little data have been published on the practice and work of dietitians in the country. This could stimulate new 
research agendas in the areas of professionalism and sustainable dietetic practices. Surveys in the field of dietetics to define the need for the development and changes within the profession is needed. Moreover, these types of surveys need to be conducted at regular intervals.

This review is an attempt to define professional needs for the fieldof dietetics. This is a critical call for professionals in the field of nutrition and dietetics, to assemble a group of leaders and thinkers, particularly dietetic educators and researchers to help in the development of professionalism and to unify the dietetic practice in Sudan.

The first nutrition and dietetics-related schools in Sudan were established since 1966. The profession currently shows important signs of the need for growth in dietetics education, nutrition and dietetic services and practice in the area. This could confirm the role of Sudanese dietetic professionals inside and outside Sudan to help in establishing an NDA in Sudan. The NDA will help in informing, protecting, representing and supporting all dietetics members. It will also help Sudanese dietitians to work within an ethical framework, define the nutrition and dietetic process, which is central to the dietetic practice. Moreover, an NDA in Sudan will facilitate dietitians engagement in continuous professional development throughout their careers and to ensure that their practice is strong, efficient and advanced.

There is large opportunities for the diaspora of Sudanese nutrition and dietetic professionals working in different geographical locations in the world (in either Western or Arab countries), to participate in providing their experience and support to enhance the professionalism and practice of dietetics in Sudan. This consequently will help in supporting future efforts to reduce the skills gap and address dietetic workforce issues in Sudan.

\section{ACKNOWLEDGEMENTS}

The author acknowledges and expresses gratitude to Dr. Asmaa Abdulla Abdulaal from the Community Medicine Department, Faculty of Medicine at University of Khartoum for her great contributions and help in collecting and consulting the author for information related to dietetic education, dietetics practice and Dietitians work in Sudan. Thanks also for her review of the collected information, which considerably strengthened this review paper. Many Thanks also to Prof. Sidiga Washi, Director Nutrition Center for Training and Research, AUW, Sudan for her help in collecting data related to the education in AUW and NCTR. The idea for this review emerged from a suggestion and discussion made with Dr. Nahlaa A. Khalifa, Assistant Professor, Clinical Nutrition Department, Faculty of Applied Medical Sciences, King Abdulaziz University, Jeddah, Saudi Arabia.

\section{REFRENCES}

A university report (University of Khartoum, Faculty of Education, Department of Family Sciences, Nutrition and Dietetics programme (Agba Abbas Ahmed Gadah Eldam). (Hard copy of the report received on April 18, 2015).

Ahfad University for Women (School of Health Science), Available at: http://www.ahfad.org/school_health_ sciences.html, Accessed on 27 March 2015.

Aljaaly, E. and Khalifa, N.A (2015) 'Nutrition \& Dietetics Services for Assessing Adolescents' Anthropometric status in Saudi Arabia', International Journal of Scientific Research (IJSR), Vol. 4, No. 4, April, ISSN No 2277 - 8179, pp.337-338, Available at: http://theglobaljournals.com/ijsr/file.php?val=April_2015_1427977645_105.pdf.

Alribat National University, Available at: https://www.facebook.com/pages/Alribat-National, Accessed on 27 March 2015. 
Anderson, J. (2013) 'Academy definition of terms: a list of terms with associated definitions and key considerations', The Journal of the Academy of Nutrition and Dietetics (JAND), Vol. 113, No. 6, p.S9.

Bloch, A.S. (2007) Issues and Choices in Clinical Nutrition Practice, Philadelphia: Lippincott Williams \& Wilkins, Chapter 7, p.136.

Debbie, M., Daphne, L. and Jacqui, G. (2011) 'Professional socialization in dietetics: a review of the literature', Canadian Journal of Dietetic Practice and Research, Vol. 72, No. 1, pp.37-42, 10.3148/72.1.2011.37.

Dietitians of Canada (2012) 'Fixing the Skills Gap: Dietitian Workforce Shortage in Canada', Accessed on March 2015, Available at: http://www.dietitians.ca/Downloads/Public/2012-06-HUMA-shortage-HHR-brief_final.aspx.

European Academic and Practitioner Standards for the education and training of dietitians throughout Europeunanimously adopted by the EFAD General Meeting 2005.

Golzynski, D.L. (2001) Defining Professionalism for Dietetic Education (2001), Michigan State University, Department of Agriculture and Natural Resources Education and Communication Systems, Book (294 pages), Available at: http://books.google.com.sa/books?id=I0-EnQEACAAJ.

HRH commitment pathways SUDAN. EMRO Report (2013) Available at: http://www.who.int/workforcealliance/ forum/2013/EMRO_Sudan.pdf, Accessed on 7 April 2015.

ICDA Reports (International Confederation of Dietetic Associations) (2008) Dietitians around the World. Their education and their work. The Education and Work of Dietitians, Available at: http://www.internationaldietetics. org/Downloads/2008-Report-on-Education-and-Work-of-Dietitians.aspx.

ICDA Reports (International Confederation of Dietetic Association) (2004) 'The education and work of dietitians', Available at: http://www.internationaldietetics.org/Downloads/Education-and-Work-of-Diettiians-2004.aspx.

Merriam-Webster's collegiate dictionary (2015) Available at: http://www.merriam-webster.com/dictionary/ professionalism, Accessed on 7 April 2015.

National Human Resources for Health (NHRH) (2001) Strategic Plan for Sudan 2012-2016. Government of Sudan Federal Ministry of Health Directorate General of Human Resources for Health Development. (2011), Directorate General of Human Resources for Health Development, Federal Ministry of Health Sudan, Available at: http:// www.hrhresourcecenter.org/node/5019.

Payne-Palacio, J. and Canter, D.D. (2000) 'Professionalism', in N.W. Marquardt (Ed.). The Profession of Dietetics: A Team Approach, pp.101-129, Upper Saddle River, NJ: Prentice-Hall, Inc.

Rodriguez, J.C., Robinson, N. and Martin, T. (2000, Fall) 'Teaching the ABCs of professionalism', DEP-LINE, Vol. 2, No. 1, pp.4-8.

Sallot, L.M., Cameron, G.T. and Weaver Lariscy, R.A. (1998) 'Pluralistic ignorance and professional standards: underestimating professionalism of our peers in public relations', Public Relations Review, Vol. 2, No. 4, pp.1-19.

Sudan - World Health Organization (2012) 'Achieving health related MDGs: Addressing health workforce challenges through the Country Coordination and Facilitation (CCF) Approach', Available at: http://www.who. int/workforcealliance/countries/ccf/Sudan_case_story2012.pdf, Accessed on 10 April 2015.

The American Dietetic Association (1999) 'Code of ethics for the profession of dietetics', Journal of the American Dietetic Association, Vol. 9, No. 9, pp.109-113.

The National Council of Medical Professions (NCMP) (2013) (A hard copy of report received on 3 April 2015). University of Khartoum, Available at: http://edu.uofk.edu/index.php?lang=en, Accessed on 27 March 2015.

Winterfeldt, E.A., Bogle, M.L. and Ebro, L.L. (2011) Dietetics: Practice and Future Trends, Sudbury, MA: Jones and Bartlett Publishers, Part II, pp.35-94, ISBN 978-0-7637-7662-6.

World Health Organization (2009) 'Country Cooperation Strategy for WHO and Sudan 2008-2013', Document WHO-EM/ARD/032/E/R/03.09, Available at: http://www.who.int/countryfocus/cooperation_strategy/ccs_sdn_ en.pdf, Accessed on 2 March 2015. 


\section{BIOGRAPHICAL NOTES}

Elham Aljaaly is Saudi national. She is an Assistant Professor and the Head of the Clinical Nutrition Department at Medical Applied College, King Abdulaziz University in Jeddah, Saudi Arabia. |The chairperson for the national and international accreditation for the Clinical Nutrition Department. A consultant editor in the IJFNPH, the track chair for the medical sciences andpublic health in the Second Sudanese Diaspora International Conference, Brighton, UK (2015). She is the first graduate Saudi dietician from the Clinical Nutrition Programme in SA. Holding an MSc in Human Nutrition from University of Sheffield andPhD in Community Nutrition and Environmental Health from University College London (UCL), London. Two Post-Doctoral programmes in Clinical Nutrition from the UK. She is a Member of different committees in the Saudi Council for Health Specialist. She has published articles on nutritional status, school and university health, obesity,media andadvertising, nutrition anddietetic practice and services. Been an invited speaker at many national, regional and international conferences since 1986 to present. 